\title{
Preparation and characterization of plasticized high molecular weight PVC-based polymer electrolytes
}

\author{
$\mathrm{S} \mathrm{RAMESH}^{a, *}$, GEOK BEE TEH ${ }^{a}$, RONG-FUH LOUH $^{b}$, \\ YONG KONG HOU ${ }^{a}$, PUNG YEN SIN ${ }^{a}$, LIM JING YI ${ }^{a}$ \\ ${ }^{a}$ Faculty of Engineering and Science, Universiti Tunku Abdul Rahman, Setapak, \\ 53300 Kuala Lumpur, Malaysia \\ ${ }^{b}$ Department of Materials Science and Engineering, Feng Chia University, 100, \\ Wenhwa Road, Seatwen, Taichung, Taiwan 40724, Republic of China \\ e-mail: ramesh@utar.edu.my
}

MS received 14 January 2008; revised 16 March 2009; accepted 31 October 2009

\begin{abstract}
Poly(vinyl chloride) (PVC)-based polymer electrolytes films consisting of lithium trifluromethanesulfonate $\left(\mathrm{LiCF}_{3} \mathrm{SO}_{3}\right)$-ethylene carbonate $(\mathrm{EC})$ were prepared by the solution-casting method. Ionic conductivities of the electrolytes have been determined by an impedance studies in the temperature range of 298$373 \mathrm{~K}$. Complexation of the prepared electrolytes is studied by $X$-ray diffraction (XRD) analysis. Thermogravimetric analysis (TGA) was used to confirm the thermal stability of the polymer electrolytes. The conductivity-temperature plots were found to follow an Arrhenius nature. All these films are found to be thermally stable until $132-167^{\circ} \mathrm{C}$.
\end{abstract}

Keywords. High molecular weight poly(vinyl chloride); plasticizer; polymer electrolyte.

\section{Introduction}

In the recent years, polymer electrolytes have been widely studied due to their applicability for a variety of solid state and electrochemical device application including batteries, fuel cells, supercapacitors, electrochromic devices and chemical sensors (Santhosh et al 2006). Polymer electrolytes have many advantages, such as flexibility, ease of processing into thin films of large surface area, electrochemical stability and leak-proof nature (Bhide \& Hariharan 2006). In the past two decades, different polymer host, such as poly(ethylene oxide) (PEO), poly(methylmethacrylate) (PMMA), poly(acrylonitrile) (PAN) and poly(vinyl chloride) (PVC) have been studied (Stephen 2006).

The widespread use of PVC is attributed mainly to the presence of lone pair electrons at the chlorine atom where inorganic salts can be solvated and the dipole-dipole interaction between the hydrogen and chlorine atoms can stiffen the polymer backbone (Uma et al 2005).

*For correspondence 
PVC allows the formation of homogeneous mixture films when blended with $\mathrm{Li}$ salt and EC plasticizer; but these gel systems are essentially thermodynamically unstable and may undergo solvent exudation upon long term storage, especially under open-atmosphere conditions. This phenomenon is known as the 'syneresis effect'. When this effect occurs, the solvent will leak to the surface of the electrolyte film and induces the film to become turbid (Li et al 2006).

Plasticized polymer electrolytes have proved to be promising as electrolytes of the lithium batteries owing to their high ionic conductivity (Sun et al 2004). The enhancement in electrical conductivity in plasticized electrolytes is explained in terms of ion association/dissociation effect and increase in the amorphous nature of the system (Pradhan et al 2005). However, such plasticized electrolytes also exhibit drawbacks, such as reactivity of polar solvents with lithium electrode, poor mechanical properties at high degree of plasticization and solvent volatility (Cha et al 2004).

In the present work, high molecular weight PVC-based film consisting of $\mathrm{LiCF}_{3} \mathrm{SO}_{3}$ and ethylene carbonate (EC) was characterized by impedance spectroscopy, XRD and TGA analysis. This is to study the conductivity, crystallinity behaviour and thermal stability of the films.

\section{Experimental procedure}

\subsection{Sample preparation}

The preparation of polymer electrolytes was carried out by solution cast technique with tetrahydrofuran (THF) as solvent. The appropriate amount of high molecular weight PVC, $\mathrm{LiCF}_{3} \mathrm{SO}_{3}$ and different ratios of EC were mixed and stirred for 24 hours to achieve a homogeneous, viscous solution. The solution thus obtained was cast on a glass plate and allowed to evaporate slowly inside a dessicator.

\subsection{Ionic conductivity measurements}

Conductivity measurement was performed by impedance spectroscopy using HIOKI Model $3532-50$ bridge interfaced to a computer for data acquisition over frequency range of $50 \mathrm{~Hz}$ to $1 \mathrm{MHz}$. The films were sandwiched between two stainless disk electrodes. The conductivity temperature study was conducted in the temperature range of $25^{\circ} \mathrm{C}$ to $100^{\circ} \mathrm{C}$.

\subsection{XRD analysis}

$X$-ray diffraction analysis was performed using Control Software MXP3 model from Japan MAC SCIENCE in the $2 \theta$ range between $5^{\circ}$ and $45^{\circ}$ with scanning rate at $5^{\circ} / \mathrm{min}$.

\subsection{TGA analysis}

Thermal stability of the electrolytes was studied using METTLER $851^{\mathrm{e}}$ TGA. The samples were put in an $\mathrm{Al}$ pan and heated from $25^{\circ} \mathrm{C}$ up to $350^{\circ} \mathrm{C}$ at the rate of $10^{\circ} \mathrm{C} / \mathrm{min}$.

\section{Results and discussion}

\subsection{Ionic conductivity}

The ionic conductivity is calculated using the equation $\sigma=l /\left(R_{B} A\right)$, where $l$ is the thickness of the polymer electrolyte film, $A$ is the surface area of the film and $R_{B}$ is the bulk electrical 


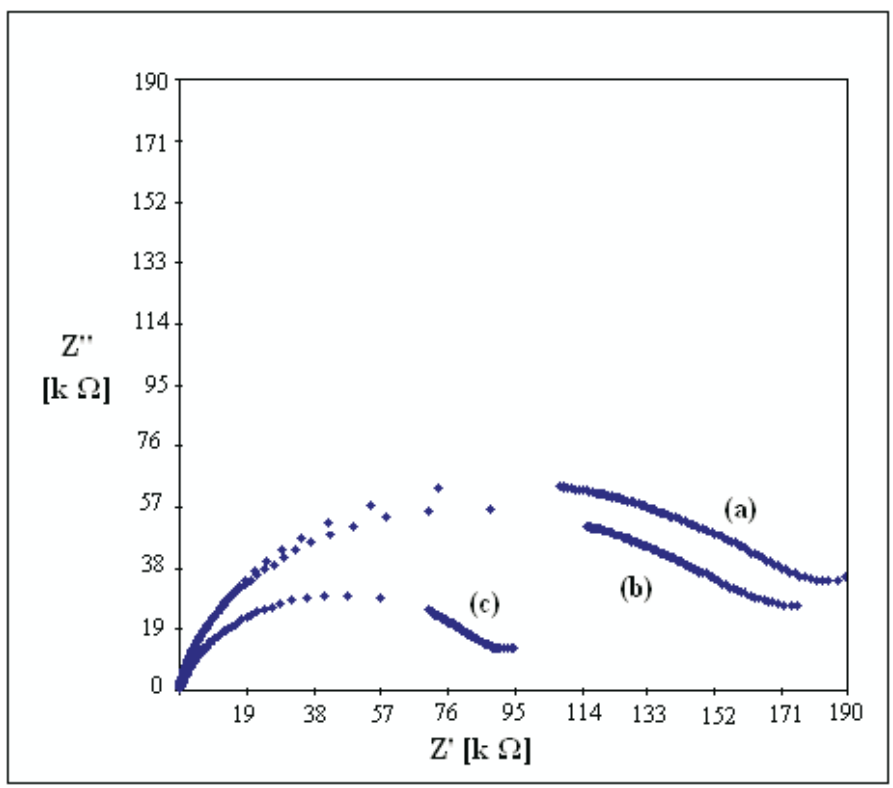

Figure 1. Impedance spectrum of $\mathrm{PVC}-\mathrm{LiCF}_{3} \mathrm{SO}_{3}: \mathrm{EC}(60: 40)$ at curve (a) $25^{\circ} \mathrm{C}$, (b) $50^{\circ} \mathrm{C}$ and (c) $70^{\circ} \mathrm{C}$.

resistance value, which can be calculated from the intercept on the $Z^{\prime}$ axis (Fan \& Maier 2006). The ionic conductivity of the polymer electrolyte depends on the effective number of carrier ions and the ions mobility. The effective number of carrier ions is related to the concentration of the dissolved ions. The ion mobility in a polymer electrolyte formed by the dissolution of ions in the polymer is facilitated by the segment mobility of the polymer chains (Santhosh et al 2006). Figure 1 shows the relationship between temperature against ionic conductivity of PVC- $\mathrm{LiCF}_{3} \mathrm{SO}_{3}$ : EC (60:40) system. As the temperature increases, the $R_{B}$ value will decrease and show a higher conductivity value according to the equation above. The conductivity at room temperature is $2.29 \times 10^{-8} \mathrm{~S} \mathrm{~cm}^{-1}$, it then rises to $2.56 \times 10^{-8} \mathrm{~S} \mathrm{~cm}^{-1}$ and subsequently $2.77 \times 10^{-8} \mathrm{~S} \mathrm{~cm}^{-1}$ as the temperature increases from room temperature to $50^{\circ} \mathrm{C}$ and $70^{\circ} \mathrm{C}$ respectively. This is due to the segmentation of the polymer network as well as an increase in the amorphous nature.

Figure 2 shows the relationship between $\log \sigma$ against 1000/ $T$ for $\mathrm{PVC}-\mathrm{LiCF}_{3} \mathrm{SO}_{3}$ : EC (75:25) and $\mathrm{PVC}-\mathrm{LiCF}_{3} \mathrm{SO}_{3}$ : EC (60:40). The regression value $R^{2}$ lies in 0.9710 and 0.9954 for 25 and $40 \mathrm{wt} . \% \mathrm{EC}$ respectively. These values are close to unity and therefore the temperature-dependent ionic conductivity for all the complexes obey Arrhenius rule, indicating that the conductivity mechanism is thermally assisted (Yahya \& Arof 2003). Since the conductivity temperature data follows Arrhenius behaviour, the nature of cation transport is quite similar to that in ionic crystals, where ions jump into neighbouring vacant sites (Ramesh et al 2002).

Figure 3 shows that the ionic conductivity increases with the increase of plasticizer content at room temperature. The maximum conductivity value of $4.02 \times 10^{-8} \mathrm{~S} \mathrm{~cm}^{-1}$ is obtained at $35 \mathrm{wt} . \%$ of the plasticizer content and decreases again at EC content of $40 \mathrm{wt} . \%$. This decrease in conductivity could be due to ion aggregation. This is because ion aggregation decreases the available number of charge carriers. It can be concluded that $\mathrm{CF}_{3} \mathrm{SO}_{3}^{-}$increases the dissociation of the $\mathrm{LiCF}_{3} \mathrm{SO}_{3}$ salt into lithium and triflate ions up to a certain concentration 


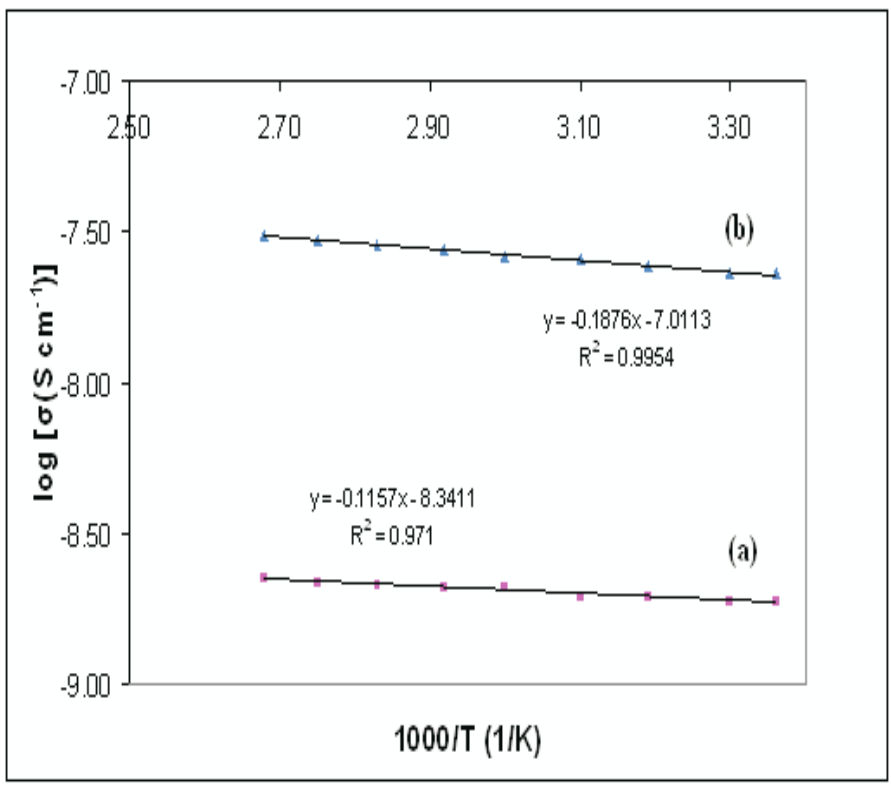

Figure 2. Temperature dependence of ionic conductivity of (a) $\mathrm{PVC}^{-} \mathrm{LiCF}_{3} \mathrm{SO}_{3}$ : $\mathrm{EC}(75: 25)$ and (b) PVC-LiCF $\mathrm{SO}_{3}$ : $\mathrm{EC}(60: 40)$.

after which ion aggregation occurs at a faster rate than ion dissociation by $\mathrm{CF}_{3} \mathrm{SO}_{3}^{-}$and reduces the number of mobile ions in the sample.

Ionic conductivity of the enhanced plasticized solid polymer electrolyte can be explained by the interaction between $\mathrm{PVC}, \mathrm{EC}$ and $\mathrm{LiCF}_{3} \mathrm{SO}_{3}$. There are three main interactions among

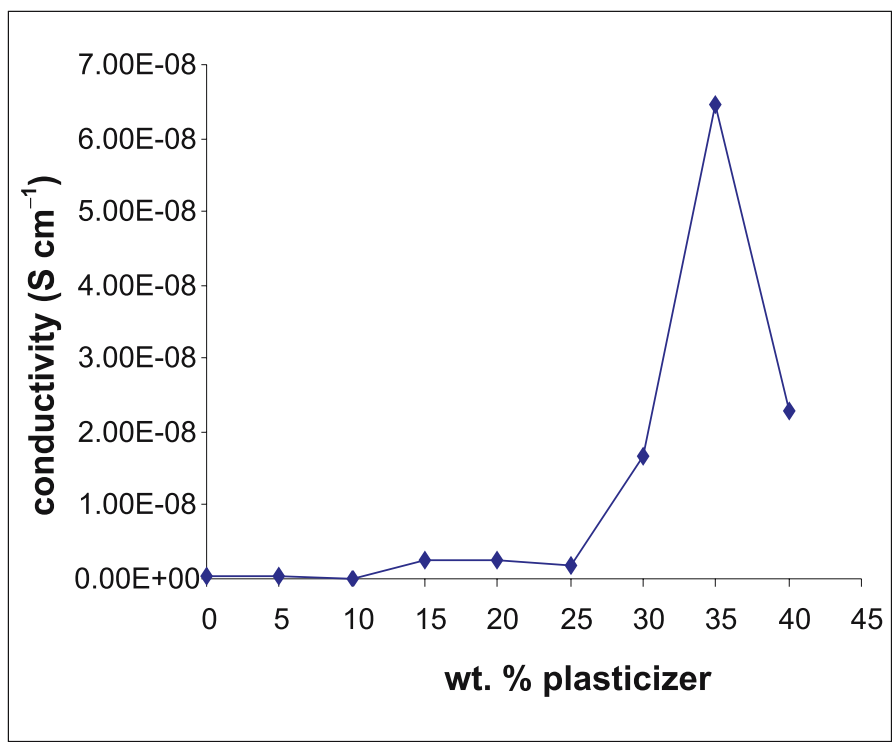

Figure 3. Variation of conductivity with plasticizer (EC) weight percentage at $25^{\circ} \mathrm{C}$. 
them: (i) ion-ion interaction between $\mathrm{Li}^{+}$cations and $\mathrm{CF}_{3} \mathrm{SO}_{3}^{-}$anions; (ii) ion-dipole interactions between $\mathrm{Li}^{+}$cations and chlorine in PVC; (iii) ion-molecule interactions between $\mathrm{Li}^{+}$and EC. These interactions are of importance to form $\mathrm{PVC}-\mathrm{LiCF}_{3} \mathrm{SO}_{3}-\mathrm{EC}$ polymer electrolyte, in which three different compounds of PVC- $\mathrm{Li}^{+}, \mathrm{PVC}-\mathrm{Li}^{+}-\mathrm{EC}$ and $\mathrm{Li}^{+}-\mathrm{EC}$ exist. The oxygen of $\mathrm{C}=\mathrm{O}$ in $\mathrm{EC}$ is an electron donor which will participate in competition with $\mathrm{CF}_{3} \mathrm{SO}_{3}^{-}$and $\mathrm{PVC}$. The $\mathrm{Li}^{+}$-EC interactions exist not only between $\mathrm{Li}^{+}$and oxygen atoms of $\mathrm{C}=\mathrm{O}$ group, but also between $\mathrm{Li}^{+}$and another two oxygen atoms in the ring structure of $\mathrm{EC}$. $\mathrm{Li}^{+}$-EC interaction plays an important role in the conductivity of $\mathrm{PVC}-\mathrm{LiCF}_{3} \mathrm{SO}_{3}-\mathrm{EC}$ system. The addition of $\mathrm{EC}$ leads to the formation of $\mathrm{Li}^{+}$-EC complex and enhances the flexibility of PVC chains by decreasing the fraction of PVC- $\mathrm{Li}^{+}$complex. The increase in flexibility is the reason why the conductivity increases with the addition of EC plasticizer (Qian et al 2002).

\section{$3.2 X R D$ analysis}

The $X$-ray diffraction analysis is used to determine the structure, complexation and crystallization of the polymer matrix (Vickraman \& Ramamurthy 2006; Pradhan et al 2005; Rajendran et al 2004). In order to investigate the effect of complexation of PVC- $\mathrm{LiCF}_{3} \mathrm{SO}_{3}-\mathrm{EC}$ system, $\mathrm{XRD}$ analysis has been performed and the respective diffraction patterns of pure high molecular weight PVC, PVC- $\mathrm{LiCF}_{3} \mathrm{SO}_{3}$ and $\mathrm{PVC}-\mathrm{LiCF}_{3} \mathrm{SO}_{3}-\mathrm{EC}$ are shown in figure 4.

For pure PVC curve, two broad amorphous peaks are formed and shown at $2 \theta=9.36^{\circ}$ and $17 \cdot 40^{\circ}$. When Li salt was added, the peaks shifted to $9.94^{\circ}$ and $18 \cdot 36^{\circ}$, respectively. Upon addition of plasticizer, the peaks shifted to $9.76^{\circ}$ and $18.50^{\circ}$. The characteristic diffraction lines for the lithium salt are absent in the PVC- $\mathrm{LiCF}_{3} \mathrm{SO}_{3}$ and $\mathrm{PVC}-\mathrm{LiCF}_{3} \mathrm{SO}_{3}-\mathrm{EC}$ complexes. This is observed from the intensity of the peaks which are same for all the three samples studied. This shows that the amorphous nature of the pure polymer is retained with the addition of salt and plasticizer. This behaviour demonstrates that complexation between PVC, $\mathrm{LiCF}_{3} \mathrm{SO}_{3}$ and $\mathrm{EC}$ occurs and takes place in the amorphous region (Rajendran et al 2004).

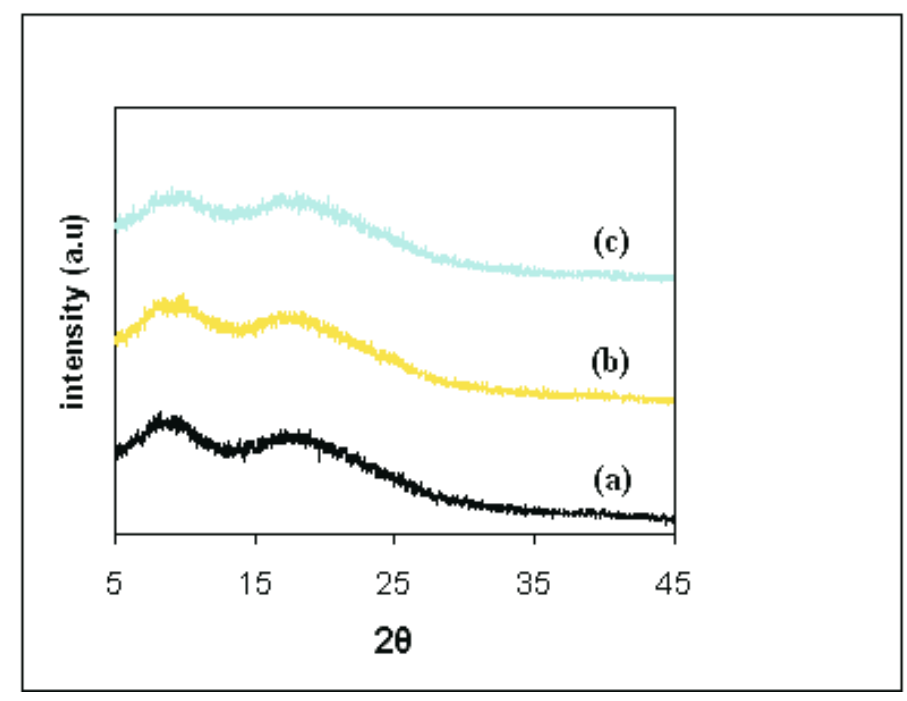

Figure 4. XRD patterns of (a) pure PVC, (b) $\mathrm{PVC}-\mathrm{LiCF}_{3} \mathrm{SO}_{3}$ and (c) $\mathrm{PVC}-\mathrm{LiCF}_{3} \mathrm{SO}_{3}-\mathrm{EC}$. 


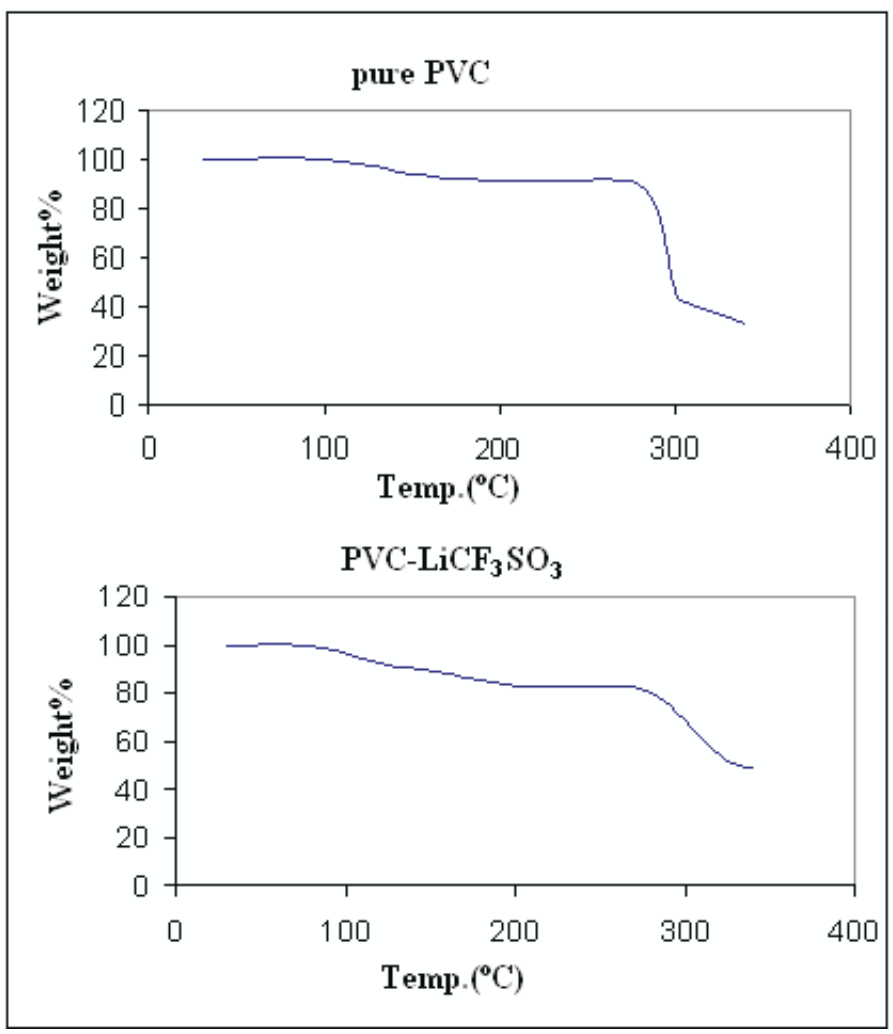

Figure 5. TGA analysis of pure PVC and $\mathrm{PVC}-\mathrm{LiCF}_{3} \mathrm{SO}_{3}$.

\subsection{TGA analysis}

TGA has been used to investigate the thermal degradation, phase transition and crystallization of the polymers. For lithium ion battery, it is necessary for the polymer electrolyte to have high thermal stability. In order to ascertain the thermal stability, the prepared films were subjected to TGA analysis (Stephen et al 2002).

The thermogravimetric curve for pure PVC and $\mathrm{PVC}-\mathrm{LiCF}_{3} \mathrm{SO}_{3}$ films are given in figure 5. The pure PVC film appears to be quite dry since its weight is almost constant up to $100^{\circ} \mathrm{C}$. Above $100^{\circ} \mathrm{C}$, i.e. after complete dehydration, no further weight loss is observed until irreversible decomposition commenced at approximately $138^{\circ} \mathrm{C}$ and shows a weight loss of $8.51 \%$. This indicates that the film is stable up to $138^{\circ} \mathrm{C}$. The loss may be due to decomposition of PVC occurred (Stephen et al 2005). When the temperature rose to $293^{\circ} \mathrm{C}$, the samples exhibit a gradual weight loss of about $60 \%$. This shows that the occurrence of another irreversible decomposition took place half of the PVC weight vanished.

For the $\mathrm{PVC}-\mathrm{LiCF}_{3} \mathrm{SO}_{3}$ film, a weight loss about $9 \%$ at $100^{\circ} \mathrm{C}$ is observed. This is due to the removal of moisture or residue solvent in the film (Uma et al 2004). The first decomposition took place at $171^{\circ} \mathrm{C}$ which induced $7 \%$ weight loss and second decomposition occurred at $304^{\circ} \mathrm{C}$ which showed weight loss of $35 \%$. Obviously, this indicates that the film is stable up to $171^{\circ} \mathrm{C}$ and demonstrates that $\mathrm{PVC}-\mathrm{LiCF}_{3} \mathrm{SO}_{3}$ is preferred in the lithium polymer batteries as its operating temperature is normally in the range of $40^{\circ} \mathrm{C}-70^{\circ} \mathrm{C}$ (Uma et al 2005). 


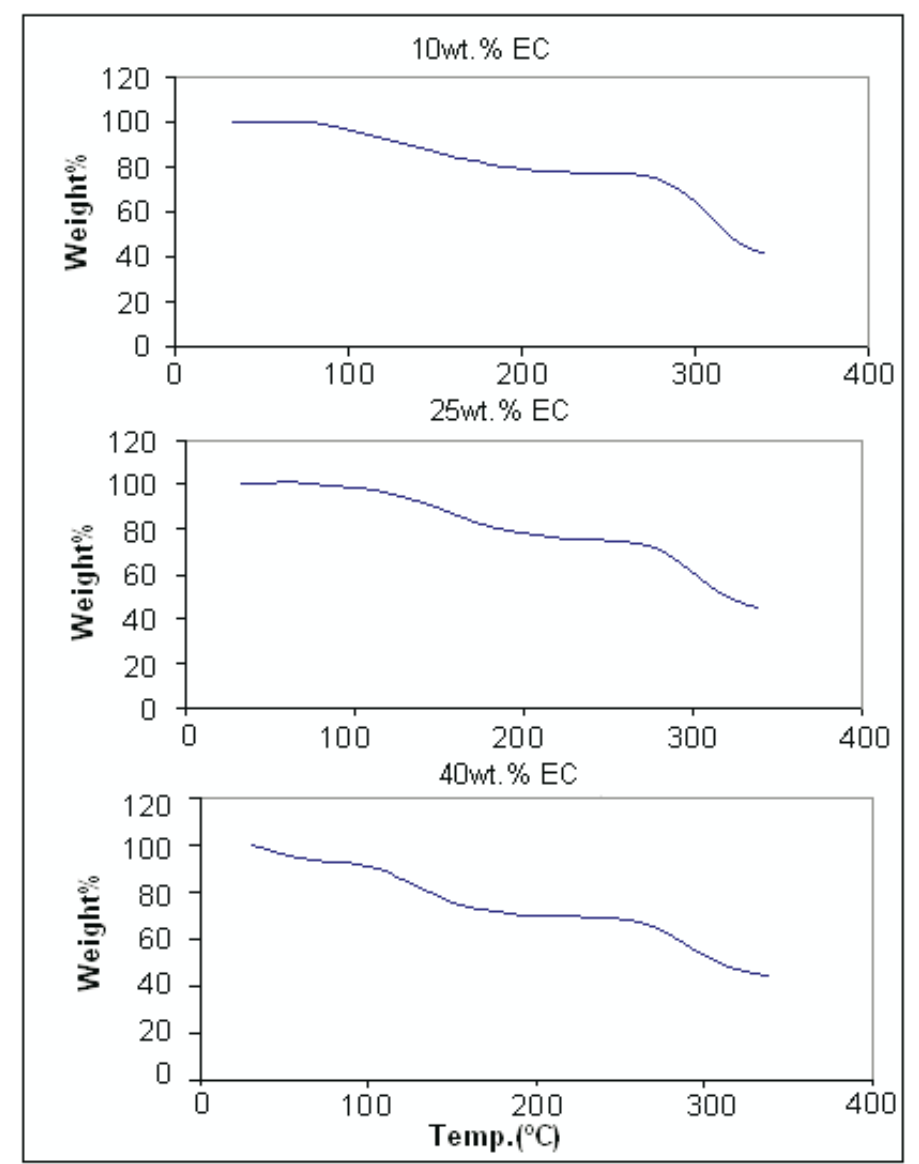

Figure 6. TGA analysis of $\mathrm{PVC}-\mathrm{LiCF}_{3} \mathrm{SO}_{3}$ : EC (90:10), $\mathrm{PVC}-\mathrm{LiCF}_{3} \mathrm{SO}_{3}: \mathrm{EC}$ (75:25) and $\mathrm{PVC}-\mathrm{LiCF}_{3} \mathrm{SO}_{3}$ : EC (60:40).

Since the first decomposition of PVC- $\mathrm{LiCF}_{3} \mathrm{SO}_{3}$ film occurred at higher temperature and bore a lower weight loss, this proves that the thermal stability increased with addition of $\mathrm{LiCF}_{3} \mathrm{SO}_{3}$.

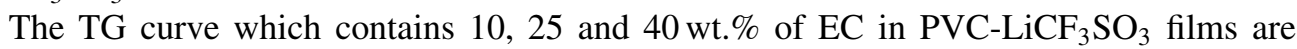
illustrated in figure 6. At temperature around $100^{\circ} \mathrm{C}$, a small amount of weight loss is observed for these three samples. This is considered as the result of loss of solvent and moisture from the electrolytes as mentioned before. The first decomposition occurred at temperature $167^{\circ} \mathrm{C}, 160^{\circ} \mathrm{C}, 132^{\circ} \mathrm{C}$ respectively which suffered weight loss from $12 \%$ to 22 and $23 \%$ as the plasticizer content increase. This shows that the thermal stability decreased with increase in plasticizer content. Subsequently, the second decomposition showed a weight loss of $25-37 \%$ at the temperature range of $291-308^{\circ} \mathrm{C}$ for all three samples.

Polymers of higher PVC content and lower plasticizer amount are proven to have a relatively good stability as they have the first decomposition at higher temperature bearing a lower weight loss. Also, the sample with $10 \mathrm{wt} \%$ EC shows the lowest ionic conductivity followed by the samples with 25 and $40 \mathrm{wt} \%$ EC. Figure 2 shows that the conductivity of $25 \mathrm{wt} \%$ EC is lower than $40 \mathrm{wt} \% \mathrm{EC}$ at all temperatures. This is due to high thermal stability of the polymer 
films which will restrict the movement of ions. Hence, it results in minimum conductivity for the high thermal stability polymer films.

\section{Conclusion}

The impedance study showed that the addition of plasticizer to the polymer electrolyte enhanced the ionic conductivity. The temperature-dependent ionic conductivity plots of the electrolyte films seem to obey Arrhenius rule. XRD analysis confirms the complexation occurred between EC, PVC and $\mathrm{LiCF}_{3} \mathrm{SO}_{3}$. TGA study showed that addition of plasticizer caused a lower thermal stability.

The authors would like to thank Feng Chia University for the UTAR-FCU Student Exchange Programme and for instrumentation facility.

\section{References}

Bhide A, Hariharan K 2006 A new polymer electrolyte system (PEO) ${ }_{n}: \mathrm{NaPO}_{3}$. J. Power Sources 159: $1450-1457$

Cha E H, Macfarlane D R, Forsyth M, Lee C W 2004 Ionic conductivity studies of polymeric electrolytes containing lithium salt with plasticizer. Electrochim. Acta 50: 335-338

Fan L Z, Maier J 2006 Composite effects in poly(ethylene oxide)-succinonitrile-based all-solid electrolytes. Electrochem. Commum. 8: 1753-1756

Li W L, Yuan M Y, Yang M J 2006 Dual-phase polymer electrolyte with enhanced phase compatibility based on Poly(MMA-g-PVC)/PMMA. Euro. Polym. J. 42: 1396-1402

Pradhan D K, Samantaray B K, Choudhary R N P, Thakur A K 2005 Effect of plasticizer on structureproperty relationship in composite polymer electrolytes. J. Power Sources 139: 384-393

Qian X M, Gu N Y, Cheng Z L, Yang X R, Wang E K, Dong S J 2002 Plasticizer effect on the ionic conductivity of PEO-based polymer electrolyte. Mater. Chem. Phys. 74: 98-103

Rajendran S, Sivakumar M, Subadevi R 2004 Investigations on the effect of various plasticizers in PVA-PMMA solid polymer blend electrolytes. Mater. Lett. 58: 641-649

Ramesh S, Yahaya A H, Arof A K 2002 Dielectric behaviour of PVC-based polymer electrolytes. Solid State Ionics 152-153, 291-294

Santhosh P, Vasudevan T, Gopalan A, Lee K P 2006 Preparation and properties of new cross-linked polyurethane acrylate electrolytes for lithium batteries. J. Power Sources 160: 609-620

Stephan A M 2006 Review on gel polymer electrolytes for lithium batteries. Euro. Polym. J. 42: 21-42

Stephan A M, Kumar S G, Renganathan N G, Kulandainathan M A 2005 Characterization of poly(vinylidene fluoride-hexafluoropropylene) (PVdF-HFP) electrolytes complexed with different lithium salts. Euro. Polym. J. 41: 15-21

Stephan A M, Saito Y, Muniyandi N, Renganathan N G, Kalyanasundaram S, Elizabeth R N 2002 Preparation and characterization of PVC/PMMA blend polymer electrolytes complexed with $\mathrm{LiN}\left(\mathrm{CF}_{3} \mathrm{SO}_{2}\right)_{2}$. Solid State Ionics 148: 467-473

Sun X G, Liu G, Xie J B, Han Y B, Kerr J B 2004 New gel polyelectrolytes for rechargeable lithium batteries. Solid State Ionics 175: 713-716

Uma T, Mahalingan T, Stimming U 2005 Solid polymer electrolytes based on poly(vinylchloride)lithium sulfate. Mater. Chem. Phys. 90: 239-244

Uma T, Mahalingam T, Stimming U 2004 Conductivity and thermal studies of solid polymer electrolytes prepared by blending polyvinylchloride, polymethylmethacrylate and lithium sulfate. Mater. Chem. Phys. 85: 131-136 
Vickraman P, Ramamurthy S 2006 A study on the blending effect of PVDF in the ionic transport mechanism of plasticized PVC-LiBF 4 polymer electrolyte. Mater. Lett. 60: 3431-3436

Yahya M Z A, Arof A K 2003 Effect of oleic acid plasticizer on chitosan-lithium acetate solid polymer electrolytes. Euro. Polym. J. 39: 897-902 